\title{
Effects of interleukin-2 concentration and administration method on proliferation and function of cytokine-induced killer cells
}

\author{
Yali Liu ${ }^{1,2,3}$, Jicheng $\mathrm{Li}^{3}$, Liangtao Zhao ${ }^{3}$, Jiarui $\mathrm{Zhu}^{3}$, Suli Liu ${ }^{4}$, Hongxia Wang ${ }^{4}$, Yong Zhang ${ }^{1,2}$ \\ ${ }^{1}$ College of Veterinary Medicine, Gansu Agricultural University, Lanzhou, China; ${ }^{2}$ Gansu Key Laboratory of Animal Generational Physiology and \\ Reproductive Regulation, Lanzhou, China; ${ }^{3}$ Lanzhou University Second Hospital, Lanzhou, China; ${ }^{4}$ Second Clinical Medical College of Lanzhou \\ University, Lanzhou, China \\ Contributions: (I) Conception and design: All authors; (II) Administrative support: Y Zhang; (III) Provision of study materials or patients: J Li, L Zhao; \\ (IV) Collection and assembly of data: Y Liu, J Zhu; (V) Data analysis and interpretation: J Li, J Zhu; (VI) Manuscript writing: All authors; (VII) Final \\ approval of manuscript: All authors. \\ Correspondence to: Yong Zhang. College of Veterinary Medicine, Gansu Agricultural University, 1\#Ying Men-cun road, Lanzhou 730070, China. \\ Email: zhangyong@gsau.edu.cn.
}

\begin{abstract}
Background: Cytokine-induced killer cells (CIKs) adoptive cell transfer (ACT) is a common malignant tumor treatment method. Interleukin-2 (IL-2) is one of the essential cytokines for CIKs cultures. In different phase of CIKs (quiescent and exponential growth), due to different active states and IL-2R expression of the CIKs surface, different doses of IL-2 are required. However, most studies, only addressed the effects of IL-2 concentrations on the function of CIKs, and the differences between varied administration methods of IL-2 have not been explored.

Methods: This study established a novel sequential administration methods for IL-2. Different concentrations of IL-2 were added during different CIKs induction phases. Then, the proliferation ability of CIKs was evaluated using cell proliferation curves. The immune phenotype was analyzed by flow cytometry (FCM), and IFN- $\gamma$ secretion ability and cytotoxicity were detected using enzyme-linked immunosorbent assay (ELISA) kits and cell counting kit-8, respectively. Multiple comparisons were conducted between each group to compare the function of CIKs in 12 experimental groups.
\end{abstract}

Results: As the IL-2 concentration increased, the number of CIKs continued to increase in each group, but the function of CIKs was not positively related to its number: CD3+ CD56+ subpopulation ratio, INF- $\gamma$ secretion ability, and cytotoxicity showed irregular changes. During the quiescent and exponential growth phases, adding 300 and 1,000 U/mL IL-2 respectively achieved powerful CIKs (cell numbers of day 16: $(384.37 \pm 2.05) \times 10^{6} / \mathrm{mL}$, proliferation: 128.12 , CD3 + CD56+ subpopulation ratio: $40.9 \%$, INF- $\gamma$ secretion ability: $542 \mathrm{pg} / \mathrm{mL}$, cytotoxicity: 40:1, 74.22).

Conclusions: Different concentrations of IL-2 had a greater influence on the biological function of CIKs in different growth phases, and it is better to add IL-2 sequentially during the quiescent and exponential growth phases of CIKs.

Keywords: Cytokine-induced killer cells (CIKs); interleukin-2 (IL-2); adoptive cell transfer (ACT); adoptive cell transfer

Submitted Mar 30, 2021. Accepted for publication Aug 09, 2021.

doi: $10.21037 /$ tcr-21-556

View this article at: https://dx.doi.org/10.21037/tcr-21-556

\section{Introduction}

In China, over 10,000 people were diagnosed with cancer on average per day or around 7.5 people each minute in 2015 (1), and malignant tumors have become one of the major diseases that present serious risks to health in China. Adoptive cell transfer (ACT) is a novel cancer treatment approach, which can stimulate or enhance a patient's immune function to kill cancer cells. Cytokine- 
induced killer cells (CIKs) are one of the most important mechanisms of ACT, which was reported by Wolf et al. in 1991 for the first time (2). They are a group of heterogeneous cells obtained by co-culturing human peripheral blood mononuclear cells (PBMCs) with various cytokines such as OKT3, IL-2, IFN- $\gamma$, etc. in vitro. They are called NK cell-like T lymphocytes, and CD3+ CD56+ subpopulation is its effector cell. In recent years, CIKs ACT has been widely used in various cancers and has yielded noticeable clinical effects (3-8) because of its strong antitumor activity and effects as a major histocompatibility complex-unrestricted (8). As is well-known, the clinical effect can be directly affected by the number and function of immune cells. At present, the CIK culture method is basically performed the same way in all laboratories; it was established by the Bone Marrow Transplant Center at Stanford University in the United States (9). In particular, IFN- $\gamma$ is added on day 0 , and IL-2, IL- 1 and CD 3 monoclonal antibodies as appropriate on day 1 . However, this method also has some limitations in practice, such as a long culture period, insufficient activity, and low killing ability. Therefore, a novel culture method of CIKs is urgently needed to facilitate the healthy development of tumor immunotherapy.

Interleukin (IL) 2 is one of the immune system's signaling molecules, and was initially named $\mathrm{T}$ cell growth factor (TCGF) $(10,11)$. It plays an important role in promoting $\mathrm{T}$ cell proliferation and function (12), and it is also an essential cytokine for CIKs growth. On the surface of activated NK cells and T cells, IL-2R is the receptor of IL-2, formed by up to three subunits $(\alpha, \beta$, and $\gamma)$. The high-affinity interaction of IL-2 and IL-2R promotes the activation of cell main signaling pathways and plays a vital role in promoting the proliferation and function of NK cells (12-14). Therefore, the concentration and administration method of IL-2 directly affect the quality of CIKs, and their clinical efficacy. The expression of IL-2R on CIKs surface has a difference in the quiescent and exponential growth phases. Therefore, we think that CIKs in different phase have different requirements for IL-2. At present, there are no uniform standards regarding the cultivation of CIKs, including IL-2 concentration and administration method. Also, no domestic and foreign studies included adjustments of IL-2 concentrations according to the different growth phases of CIKs in research.

This study performed a novel sequential addition: IL-2 with different concentrations in different CIKs growth phases (quiescent and exponential growth phases). The study had two primary aims: (I) to explore the relationship between concentration and administration method of IL-2 and CIKs function; and (II) to establish a new cultural approach to obtain CIKs with the best proliferation capacity, activity and cytotoxicity. We present the following article in accordance with the MDAR checklist (available at https://dx.doi.org/10.21037/tcr-21-556).

\section{Methods}

\section{CIKs induction}

The study was conducted in accordance with the Declaration of Helsinki (as revised in 2013). The study was approved by the Human Research Ethics committee of Lanzhou University Second Hospital (ethics approval number: 2017A044). Informed consent was obtained from all individual participants included in the study. PBMCs were obtained using Ficoll-Hypaque density centrifugation. Cells were resuspended at $1 \times 10^{6} \mathrm{CFU} / \mathrm{mL}$ in $\mathrm{X}-\mathrm{VIVO}-20$ media (Lonza, Basel, Switzerland) with 1,000 U/mL interferon- $\gamma$ (IFN- $\gamma$, Peprotech, Rocky Hill, NJ, USA) for the first $24 \mathrm{~h}$. On day 1, $50 \mathrm{ng} / \mathrm{mL}$ anti-CD3 monoclonal antibody (OKT3, Peprotech, Rocky Hill, NJ, USA), 100 U/mL interleukin-1 $\alpha$ (IL-1 $\alpha$, Peprotech, Rocky Hill, NJ, USA) and IL-2 (Peprotech, Rocky Hill, NJ, USA) were added to the medium. Cells were cultured in $5 \% \mathrm{CO}_{2}$ at $37{ }^{\circ} \mathrm{C}$, and fresh medium and IL-2 were added every two days. The concentration of IL-2 was 300,500 , and $1,000 \mathrm{U} / \mathrm{mL}$ in the first week; and $300,500,1,000,3,000$, and $6,000 \mathrm{U} / \mathrm{mL}$ in the second week, respectively. CIKs were harvested on day 16.

\section{Proliferation of CIKs}

Cell morphology was observed regularly, and the survival rate of CIKs was calculated by trypan-blue exclusion. Then, cell proliferation curves were drawn based on cell counting (proliferation fold $=$ number of cells after proliferation/ number of cells before proliferation). Each experiment was repeated 3 times, the results were expressed as $\bar{x} \pm$.

\section{The immune phenotype of CIKs}

CIKs from each group were harvested $\left(1 \times 10^{6} \mathrm{CFU} / \mathrm{mL}, 100 \mu \mathrm{L}\right)$ on day 16 and incubated for $30 \mathrm{~min}$ at $4{ }^{\circ} \mathrm{C}$ with antiCD3-fluorescein isothiocyanate (FITC) and anti-CD56Phycoerythrin (PE) (BD Bioscience, Frankling Lakes, NJ, USW). After washing twice, the immune phenotype of 


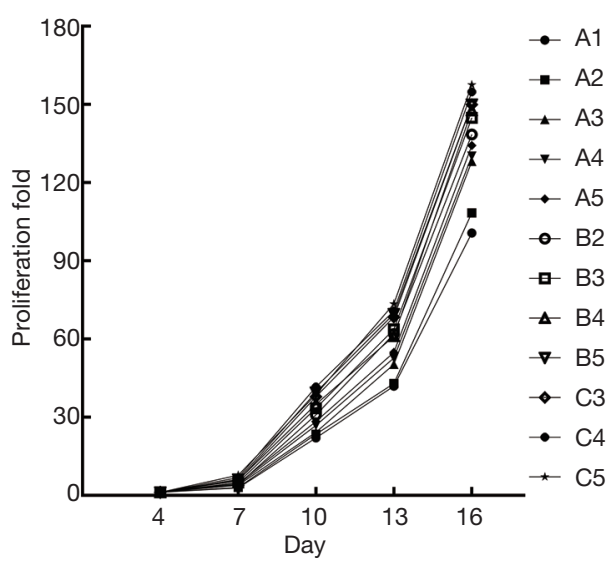

Figure 1 The proliferation curves of CIKs in different experiment groups. (A1-A5, B2-B5, C3-C5) Different experimental groups. CIKs, cytokine-induced killer cells.

CIKs was characterized using flow cytometry (FCM, BD FACSCalibur, San Jose, CA, USA), and data analysis was performed with FlowJo V10 (Ashland, OR, USA). Each experiment was repeated 3 times.

\section{IFN- $\gamma$ secretion ability of CIKs}

The expression levels of INF- $\gamma$ were determined by enzyme-linked immunosorbent assay (ELISA, Proteintech, Rosemont, IL, USA): CIKs on day 16 from each group were harvested $\left(1 \times 10^{6} \mathrm{CFU} / \mathrm{mL}\right)$. One hundred $\mu \mathrm{L}$ of the sample was added into each well coated with antibody, and the plate was incubated at $37^{\circ} \mathrm{C}$ for $120 \mathrm{~min}$; by washing 4 times, $100 \mu \mathrm{L}$ of detection antibody-biotinylated was added into each well, then the plate was incubated at $37{ }^{\circ} \mathrm{C}$ for $60 \mathrm{~min}$; after washing, streptavidin-HRP solution $(100 \mu \mathrm{L}$ per well) was added followed by incubation for 30 mins; having washed again, 3,3',5,5'-tetramethylbenzidine (TMB) substrate was added, and plates were placed into a dark room for 15 mins; stop solution was added and the optical density (OD) value was detected at $450 \mathrm{~nm}$. Each experiment was repeated 3 wells, and the results were expressed as $\bar{x} \pm \mathrm{s}$.

\section{Cytotoxicity of CIKs}

Cytotoxicity assay was performed using cell counting kit-8 (CCK-8 Kit, Yeasen Biotechnology, Shanghai, China). CIKs from each group were collected at different concentrations and used as effector cells. Gastric cancer cells (MKN45) at the exponential growth phase were used as target cells. The target cells were applied to react with effector cells at an effector-target ratio (E:T) of 10:1, 20:1, 40:1, 80:1, and 160:1. All samples were added to a 96-well plate and cultured in $5 \% \mathrm{CO}_{2}$ at $37{ }^{\circ} \mathrm{C}$. After $24 \mathrm{~h}, 20 \mu \mathrm{L}$ CCK-8 solution was added to each well and continued to be cultured for $4 \mathrm{~h}$. Then, OD value of each well was detected at $450 \mathrm{~nm}$. Cytotoxicity of CIKs was calculated using the formula: cytotoxicity $=[1-(\mathrm{OD}$ experimental group - OD effector group)/OD control group] $\times 100 \%$. Each experiment was repeated 3 wells, and the results were expressed as $\bar{x} \pm \mathrm{s}$.

\section{Statistical analyses}

Statistical analyses were performed with GraphPad Prism 7.00. Proliferation curve data were analyzed by linear regression (growth days were the independent variable, and proliferation was the dependent variable). For cytokine assay data a one-way analysis of variance (ANOVAs) was used. For cytotoxicity analysis, two-way ANOVAs were used. Multiple comparisons were carried out using Dunnett's multiple comparisons tests (multiple comparisons tests were performed between groups with the highest $\mathrm{CD} 3+\mathrm{CD} 56$ ratio, the highest IFN- $\gamma$ production, the best cytotoxicity, and the other groups). $\mathrm{P}$ values were one-sided and $\mathrm{P}<0.05$ was considered as indicating significant differences; $\mathrm{P}<0.01$ was considered as a highly significant difference; $\mathrm{P}>0.05$ was considered as not indicating a significant difference (3).

\section{Results}

\section{Proliferation of CIKs}

The viability of CIKs in each group was greater than $95 \%$. In all groups, the proliferation ability of CIKs increased with the concentration of IL-2; the high concentration of IL-2 groups showed a better growth tendency, and its proliferation could reach 157.54 on day 16 (Figure 1, Table 1).

\section{The immune phenotype of CIKs}

The results of FCM analysis showed that group A3 had the highest $\mathrm{CD} 3+\mathrm{CD} 56+$ subpopulation ratio (40.9\%); in multiple comparisons test, there was a highly significant difference between group $\mathrm{A} 3$ and the other groups $(\mathrm{P}<0.01)$. Groups A2 and A4 showed a higher ratio (30-40\%); groups $\mathrm{A} 1, \mathrm{~A} 5, \mathrm{~B} 2$, and $\mathrm{B} 3$ showed a medium ratio $(20-30 \%)$; groups B4, C3, and C4 showed a lower ratio (15-20\%); 
Table 1 IL-2 concentration and CIKs numbers of 12 experimental groups

\begin{tabular}{|c|c|c|c|c|c|c|c|}
\hline Group & \multicolumn{2}{|c|}{ Dose of IL-2 (U/mL) } & \multicolumn{5}{|c|}{ Cell numbers in different time point $\left(\times 10^{6} / \mathrm{mL}\right.$, mean $\left.\pm \mathrm{SD}\right)$} \\
\hline $\mathrm{A} 1$ & 300 & 300 & $3.40 \pm 0.01$ & $8.63 \pm 0.36$ & $66.30 \pm 1.67$ & $125.77 \pm 1.98$ & $302.11 \pm 2.92$ \\
\hline A2 & 300 & 500 & $3.40 \pm 0.02$ & $9.15 \pm 0.67$ & $70.52 \pm 1.38$ & $128.74 \pm 2.60$ & $325.07 \pm 3.84$ \\
\hline A3 & 300 & 1,000 & $3.42 \pm 0.02$ & $11.68 \pm 1.26$ & $72.50 \pm 2.26$ & $150.88 \pm 1.50$ & $384.37 \pm 2.05$ \\
\hline A5 & 300 & 6,000 & $3.48 \pm 0.02$ & $13.65 \pm 0.89$ & $85.13 \pm 2.97$ & $164.59 \pm 2.22$ & $402.66 \pm 3.30$ \\
\hline B2 & 500 & 500 & $3.52 \pm 0.01$ & $12.59 \pm 0.76$ & $92.68 \pm 2.07$ & $185.82 \pm 1.35$ & $415.31 \pm 2.28$ \\
\hline B3 & 500 & 1,000 & $3.49 \pm 0.02$ & $14.72 \pm 0.02$ & $100.28 \pm 2.74$ & $191.14 \pm 2.14$ & $434.49 \pm 2.19$ \\
\hline B4 & 500 & 3,000 & $3.53 \pm 0.02$ & $17.43 \pm 0.48$ & $104.94 \pm 3.77$ & $183.14 \pm 2.13$ & $443.03 \pm 1.41$ \\
\hline $\mathrm{C} 4$ & 1,000 & 3,000 & $3.53 \pm 0.03$ & $20.37 \pm 1.14$ & $124.78 \pm 1.37$ & $212.18 \pm 1.59$ & $464.64 \pm 2.57$ \\
\hline C5 & 1,000 & 6,000 & $3.54 \pm 0.01$ & $23.39 \pm 0.45$ & $116.22 \pm 1.73$ & $220.58 \pm 2.02$ & $472.63 \pm 1.55$ \\
\hline
\end{tabular}

IL-2, interleukin-2; CIKs, cytokine-induced killer cells. SD, standard deviation.

and group B5 and C5 showed the lowest ratio (12.5, 10\%) (Figure 2).

\section{IFN- $\gamma$ secretion ability of CIKs}

The result of IFN- $\gamma$ secretion ability are shown in Figure 3: (I) group A3 had the highest IFN- $\gamma$ production $(542 \mathrm{pg} / \mathrm{mL})$; (II) multiple comparisons showed that no significant differences were found between groups A3 and A2, B2, and B3 $(\mathrm{P}>0.05)$, and a highly significant difference was found between group $\mathrm{A} 3$ and the others groups $(\mathrm{P}<0.01)$.

\section{Cytotoxicity of CIKs}

In each group (Figure 4), the lowest cytotoxicity appeared at $\mathrm{E}: \mathrm{T}=10: 1$; after that, cytotoxicity increased as $\mathrm{E}: \mathrm{T}$ increased, and it reached the highest cytotoxicity at 40:1, but gradually decreased at 80:1 and 160:1. Then multiple comparisons were performed between the best E:T (40:1) and the others $(10: 1,20: 1,80: 1,160: 1)$ to compare the cytotoxicity of CIKs: (I) in all groups, the cytotoxicity of $\mathrm{E}: \mathrm{T}=40: 1$ was significantly better than 10:1 and 20:1 $(\mathrm{P}<0.01)$; (II) $\mathrm{E}: \mathrm{T}=40: 1$ showed better cytotoxicity than 80:1 in groups $\mathrm{A} 3$ and $\mathrm{C} 4(\mathrm{P}<0.05)$, and it was better in group $\mathrm{C} 3(\mathrm{P}<0.01)$; also this superiority was not obvious in the other groups $(\mathrm{P}>0.05)$; (III) the cytotoxicity of 40:1 was significantly better than $160: 1$ in groups $\mathrm{A} 4, \mathrm{~B} 3$, and B4 $(\mathrm{P}<0.05)$; this superiority was not significantly different in group $\mathrm{B} 2(\mathrm{P}>0.05)$, and was highly significant in the other groups $(\mathrm{P}<0.01)$.

On the other hand, with a constant E:T (Figure 5), group A3 showed better cytotoxicity; then we compared group A3 with the others: (I) when E:T=10:1, there was a highly significant difference between $\mathrm{A} 3$ and the other groups $(\mathrm{P}<0.01)$; (II) at 20:1, no difference was found between group A3 A1, and A2, but highly significant differences were found for the others $(\mathrm{P}<0.01)$; (III) at 40:1 and 80:1, no significant differences were found between the groups $\mathrm{A} 3$ and A2, and highly significant differences were found for the others $(\mathrm{P}<0.01)$; (IV) at 160:1, no significant differences were found between group A3, A1, A2, and A4; however highly significant differences were found for the others $(\mathrm{P}<0.01)$.

\section{Discussion}

IL-2 is a multicellular cytokine with a multi-directional function; interacting with its receptor IL-2R can promote cell proliferation and enhance cell activity. To date, there is no uniform standard on the concentration of IL-2 in CIKs culture. Li et al. (15) and Wang et al. (16) used $80 \mathrm{ng} / \mathrm{mL}$ and $300 \mathrm{U} / \mathrm{mL}$ IL-2, respectively, to cultivate CIKs. The 

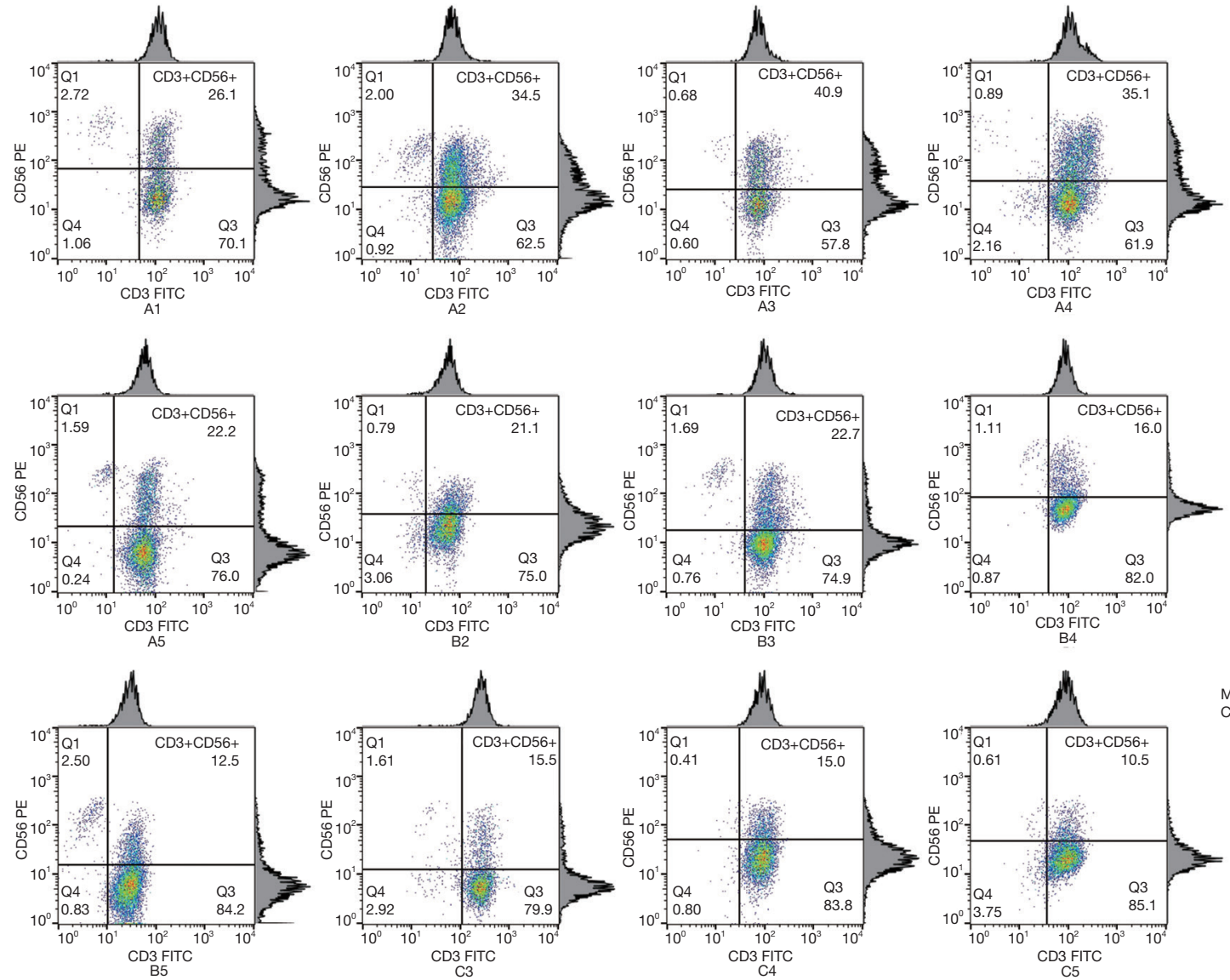

Multiple comparisons test Control group: A3

A3 vs. A1 **

A3 vs. A2 *

A3 vs. A4 **

A3 vs. B2 **

A3 vs. B3 *

A3 vs. B4 *

A3 v. C 3

A3 vs. C4 **

Figure 2 The result of flow cytometry of CD3+CD56+ cell in CIKs on day 16. (A1-A5, B2-B5, C3-C5) Different experimental groups. CIKs, cytokine-induced killer cells. ${ }^{* *}, \mathrm{P}<0.01$ was considered as high significant difference.

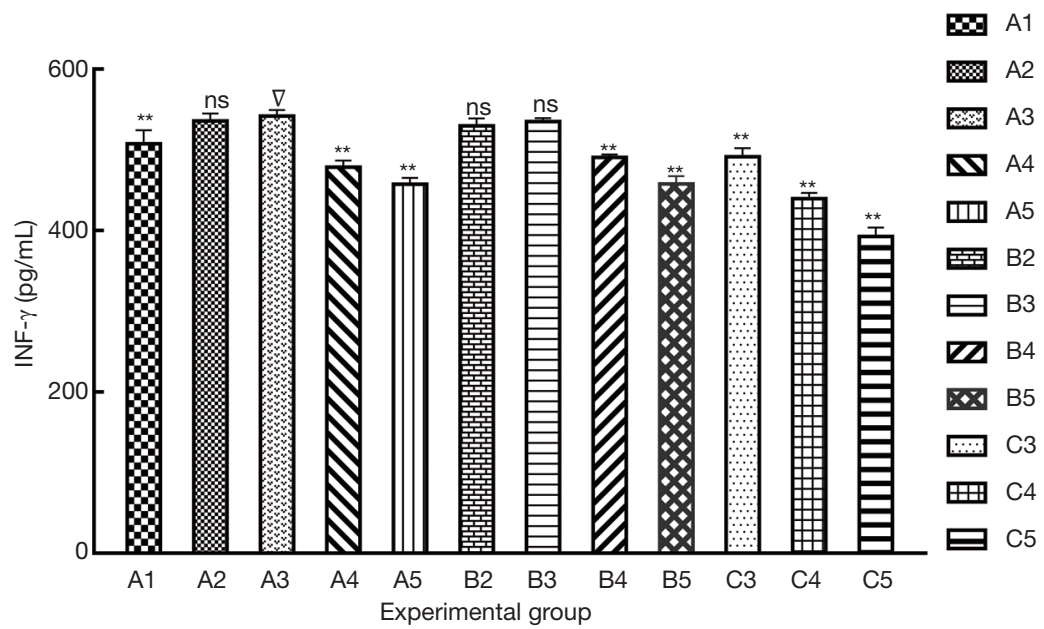

Figure 3 IFN- $\gamma$ secretion ability of CIKs in different experiment groups. (A1-A5, B2-B5, C3-C5) Different experimental groups. *, P<0.05 was considered as significant difference; ${ }^{* *}, \mathrm{P}<0.01$ was considered as high significant difference; ns, $\mathrm{P}>0.05$ was considered to be not a significant difference; $\nabla$, Dunnett's multiple comparisons test was performed between group A3 and other groups. IFN- $\gamma$, interferon- $\gamma$; CIKs, cytokine-induced killer cells. 
concentration of IL-2 in Niu et al.'s (17) experiment was $400 \mathrm{U} / \mathrm{mL}$, and the dendritic cells-cytokine-induced killers (DC-CIKs) ACT yielded good results in pancreatic cancer treatment. In other studies, its concentration was 500 or $1,000 \mathrm{U} / \mathrm{mL}(18,19)$. Recently, a large and growing body of studies has investigated the effects of different concentrations of IL-2 on CIKs. Vitolo et al. (20) considered a concentration greater than $500 \mathrm{U} / \mathrm{mL}$ as beneficial to the expansion of NK cells in vitro. Research by Xiong et al. (21) showed that when IL-2 concentration was less than 1,000 $\mathrm{U} / \mathrm{mL}$, there was no correlation between IL-2 and killing activity of NK cells; and high concentrations of IL-2 $(\geq 1,000 \mathrm{U} / \mathrm{mL}$ ) could further activate the killing activity of purified NK cells in vitro. However, some researchers (22) found that $500 \mathrm{U} / \mathrm{mL}$ was best. Other studies (23) obtained the strongest proliferation ability of CIKs when IL-2 was $1,000 \mathrm{U} / \mathrm{mL}$. According to Zoll et al. (24), the appropriate

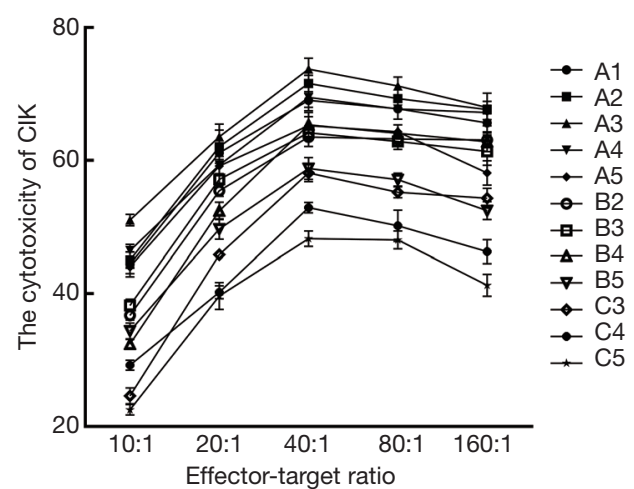

Figure 4 The cytotoxicity of CIKs in different groups. (A1-A5, B2-B5, C3-C5) Different experimental groups. CIKs, cytokineinduced killer cells.
IL-2 concentration in CIKs culture was $67-500 \mathrm{U} / \mathrm{mL}$. Nevertheless, other researchers hold the opposing view that different concentrations of IL-2 have little effect on the cytotoxicity of CIKs (25). It is worth mentioning that although extensive research has been carried out on this question, no domestic and foreign studies included adjustment of IL-2 concentrations according to different growth phases of CIKs.

In this study, we added IL-2 sequentially during CIKs culture and our research demonstrated that: (I) IL-2 concentration was proportional to CIKs proliferation capacity, however, CIKs did not have a powerful cytotoxicity; instead, INF- $\gamma$ secretion ability and cytotoxicity decreased when IL-2 was over a certain concentration; (II) in the quiescent phase of CIKs, low-concentrations of IL-2 (300 U/mL) could enhance its CD 3 + CD56 + subpopulation ratio, INF- $\gamma$ secretion ability, and cytotoxicity; (III) in the exponential growth phase, low-concentration IL-2 (300, $500 \mathrm{U} / \mathrm{mL}$ ) had no advantages, also high concentrations $(3,000,6,000 \mathrm{U} / \mathrm{mL})$ were not suitable for CIKs growth; (IV) with a consistent IL-2 concentration of CIKs in the quiescent phase, the $\mathrm{CD} 3+\mathrm{CD} 56$ + subpopulation ratio and INF- $\gamma$ secretion ability were reduced when the IL-2 concentration of the exponential growth phase was greater than 3,000 U/mL; and CD3 + CD56 + subpopulation ratio, INF- $\gamma$ secretion ability, and cytotoxicity were lowest, when IL-2 concentration of exponential growth phase was $6,000 \mathrm{U} / \mathrm{mL}$.

In summary, our study indicated that CIKs need different doses of IL-2 in different phases. Why did these phenomena occur? The first reason is the quiescent phase of CIKs, and cells are mostly at rest, the T cell surface is not activated, and it does not express or only weakly expresses IL-2R. In

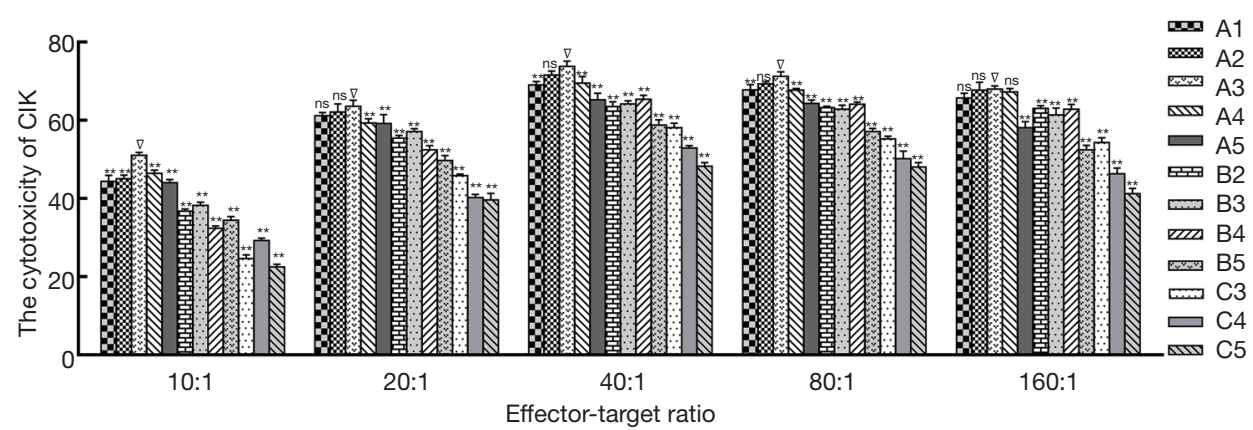

Figure 5 The cytotoxicity of CIKs at different effector-target ratio. (A1-A5, B2-B5, C3-C5) Different experimental groups. *, P<0.05 was considered as significant difference; ${ }^{*}, \mathrm{P}<0.01$ was considered as high significant difference; $\mathrm{ns}, \mathrm{P}>0.05$ was considered to be not a significant difference; $\nabla$, Dunnett's multiple comparisons test was performed between group A3 and other groups. CIKs, cytokine-induced killer cells. 
the quiescent phase, multiple cytokines (OKT3, TNF $\alpha$ ) are added to induce the expression of IL-2R, but this process takes time, and as such, there is not enough IL-2R during this phase. The affinity between IL-2R $\beta$ and IL-2R $\gamma$ expressed by NK cells and IL-2 was lower, which means that IL-2 has a weak effect on T cells and NK cells. Briefly, more IL-2 is not always better in the quiescent phase of CIKs, and large amounts of IL-2 may cause cell intolerance, and hence, we recommend stimulating CIKs with low-concentration IL-2 (300 U/mL), and increasing the IL-2 concentration after NK and T cells are fully activated. Second, the second week is the exponential growth phase of CIKs; CD69, CD25, and CD71 are upregulated after $\mathrm{T}$ cells undergo early, mediumterm and late activation, and then the CD25 will constitute a high-affinity IL-2R with IL-2R $\beta$ and IL-2R $\gamma$ chain together (26-28). Meanwhile, after being fully activated, NK cells also express the high affinity receptor IL-2R $\alpha$. Another reason is that more IL-2 can induce target cells to increase IL-2R expression. In particular, in the exponential growth phase, the affinity between IL-2 and IL-2R could theoretically increase with the increase of the IL-2 concentration; nevertheless, our study demonstrated that medium concentration of IL-2 $(1,000 \mathrm{U} / \mathrm{mL})$ showed better experimental results than high concentrations $(3,000,6,000 \mathrm{U} / \mathrm{mL})$, and the reason may be that excess IL-2 might induce enrichment of Treg cells $(29,30)$.

There are some limitations to the current study. (I) CIKs can be obtained from peripheral blood, umbilical cord blood, and bone marrow. This study only evaluated peripheral blood CIKs and did not research CIKs from other sources. (II) This study only conducted cell experiments (in-vitro experiments). It did not involve animal experiments (in-vivo experiments), also we did not monitor immune function, tumor size, overall survival, adverse reactions, etc. (III) It does not address relevant mechanisms. Notwithstanding these limitations and shortcomings, the results of cell experiments indicated that CIKs obtained by this method have good activity and strong functions.

Up to now, there are no consistent laboratory and clinical operating procedures and standards for CIKs ACT. We established a sequential administration method of of IL-2 to the CIKs culture (quiescent phase: $300 \mathrm{U} / \mathrm{mL}$, exponential growth phase: $1,000 \mathrm{U} / \mathrm{mL}$ ), which can effectively promote proliferation ability, increase CD $3+\mathrm{CD} 56+$ subpopulation ratio, and enhance INF- $\gamma$ secretion ability and cytotoxicity of CIKs. This sequential method can not only meet the basic needs of CIKs growth, but can also adjust IL-2 concentration according to the IL-2R expression of $\mathrm{T}$ cells in different phases, thereby reducing the experimental cost. In the future, we will focus on how to obtain sufficient CIKs in the most economical way to promote the clinical application of CIKs ACT.

\section{Acknowledgments}

We thank Yingying Wang and Tao Liu for their contributions. The authors would like to thank the members of the Cuiying Biomedical Research Center for providing their platforms.

Funding: This study was funded by the Cuiying Scientific and Technological Innovation Program of Lanzhou University Second Hospital (grant number CY2019-QN13), the Provincial Youth Science and Technology Fund (grant number 20JR5RA322), and the Cuiying Scientific Training Program for Undergraduates of Lanzhou University Second Hospital (grant number CYXZ-43).

\section{Footnote}

Reporting Checklist: The authors have completed the MDAR checklist. Available at https://dx.doi.org/10.21037/tcr-21-556

Data Sharing Statement: Available at https://dx.doi. org/10.21037/tcr-21-556

Peer Review File: Available at https://dx.doi.org/10.21037/ tcr-21-556

Conflicts of Interest: All authors have completed the ICMJE uniform disclosure form (available at https://dx.doi. org/10.21037/tcr-21-556). The authors have no conflicts of interest to declare.

Ethical Statement: The authors are accountable for all aspects of the work in ensuring that questions related to the accuracy or integrity of any part of the work are appropriately investigated and resolved. The study was conducted in accordance with the Declaration of Helsinki (as revised in 2013), and it was approved by the Human Research Ethics Committee of Lanzhou University Second Hospital (ethics approval number: 2017A-044). Informed consent was obtained from all individual participants included in the study.

Open Access Statement: This is an Open Access article distributed in accordance with the Creative Commons Attribution-NonCommercial-NoDerivs 4.0 International 
License (CC BY-NC-ND 4.0), which permits the noncommercial replication and distribution of the article with the strict proviso that no changes or edits are made and the original work is properly cited (including links to both the formal publication through the relevant DOI and the license). See: https://creativecommons.org/licenses/by-nc-nd/4.0/.

\section{References}

1. Chen W, Zheng R, Zhang S, et al. Cancer incidence and mortality in China in 2013: an analysis based on urbanization level. Chin J Cancer Res 2017;29:1-10.

2. Schmidt-Wolf IG, Negrin RS, Kiem HP, et al. Use of a SCID mouse/human lymphoma model to evaluate cytokine-induced killer cells with potent antitumor cell activity. J Exp Med 1991;174:139-49.

3. Liu YL, Yang LX, Zhang F, et al. Clinical effect and safety of dendritic cell-cytokine-induced killer cell immunotherapy for pancreatic cancer: a systematic review and meta-analysis. Cytotherapy 2019;21:1064-80.

4. Rosenberg SA, Restifo NP. Adoptive cell transfer as personalized immunotherapy for human cancer. Science 2015;348:62-8.

5. Khalil DN, Smith EL, Brentjens RJ, et al. The future of cancer treatment: immunomodulation, CARs and combination immunotherapy. Nat Rev Clin Oncol 2016;13:273-90.

6. Pan QZ, Liu Q, Zhou YQ, et al. CIK cell cytotoxicity is a predictive biomarker for CIK cell immunotherapy in postoperative patients with hepatocellular carcinoma. Cancer Immunol Immunother 2020;69:825-34.

7. Li N, Tian YW, Xu Y, et al. Combined Treatment with Autologous CIK Cells, Radiotherapy and Chemotherapy in Advanced Cervical Cancer. Pathol Oncol Res 2019;25:691-6.

8. Bremm M, Pfeffermann LM, Cappel C, et al. Improving Clinical Manufacturing of IL-15 Activated CytokineInduced Killer (CIK) Cells. Front Immunol 2019;10:1218.

9. Lu PH, Negrin RS. A novel population of expanded human $\mathrm{CD} 3+\mathrm{CD} 56+$ cells derived from $\mathrm{T}$ cells with potent in vivo antitumor activity in mice with severe combined immunodeficiency. J Immunol 1994;153:1687-96.

10. Mier JW, Gallo RC. Purification and some characteristics of human T-cell growth factor from phytohemagglutininstimulated lymphocyte-conditioned media. Proc Natl Acad Sci U S A 1980;77:6134-8.

11. Morgan DA, Ruscetti FW, Gallo R. Selective in vitro growth of $\mathrm{T}$ lymphocytes from normal human bone marrows. Science 1976;193:1007-8.

12. Orozco Valencia A, Camargo Knirsch M, Suavinho Ferro E, et al. Interleukin-2 as immunotherapeutic in the autoimmune diseases. Int Immunopharmacol 2020;81:106296.

13. Gaffen SL. Signaling domains of the interleukin 2 receptor. Cytokine 2001;14:63-77.

14. Ai SZ. Effect and Mechanism of Interleukin 21 on Cytokine Induced Killer against Leukemic K562 Cells. Lanzhou University 2017.

15. Li Y, Schmidt-Wolf IG, Wu YF, et al. Optimized protocols for generation of cord blood-derived cytokine-induced killer/natural killer cells. Anticancer Res 2010;30:3493-9.

16. Wang M, Shi SB, Qi JL, et al. S-1 plus CIK as secondline treatment for advanced pancreatic cancer. Med Oncol 2013;30:747.

17. Niu L, Chen J, He L, et al. Combination treatment with comprehensive cryoablation and immunotherapy in metastatic pancreatic cancer. Pancreas 2013;42:1143-9.

18. Wei C, Wang W, Pang W, et al. The CIK cells stimulated with combination of IL-2 and IL-15 provide an improved cytotoxic capacity against human lung adenocarcinoma. Tumour Biol 2014;35:1997-2007.

19. Yin X, Xu X, Zhao Y, et al. Comparison of Several Optimization Schemes for the Induction and Expansion of Antibody-Mediated High Efficiency CIK (AMHECIK) In Vitro. Zhongguo Shi Yan Xue Ye Xue Za Zhi 2016;24:191-6.

20. Vitolo D, Vujanovic NL, Rabinowich H, et al. Rapid Il-2-induced adherence of human natural killer cells. Expression of mRNA for cytokines and IL-2 receptors in adherent NK cells. J Immunol 1993;151:1926-37.

21. Xiong D, Yang ZG, Li QH, et al. Method for expansion in vitro of CD3-CD56+CD16+NK cells highly purified from human peripheral blood. Zhongguo Shi Yan Xue Ye Xue Za Zhi 2010;18:1310-5.

22. Carlens S, Gilljam M, Chambers BJ, et al. A new method for in vitro expansion of cytotoxic human CD3-CD56+ natural killer cells. Hum Immunol 2001;62:1092-8.

23. Xu LQ, Li JH, Ni XW, et al. Optimization of cytokineinduced killer cell differentiation in vitro. Chin J Blood Transfusio 2015;28:1030-3.

24. Zoll B, Lefterova P, Ebert O, et al. Modulation of cell surface markers on NK-like T lymphocytes by using IL-2, IL-7 or IL-12 in vitro stimulation. Cytokine 2000;12:1385-90.

25. Dai H, Shen LQ, Zhuang ZX, et al. Influence of Different Cultivate Conditions on Cytokine-induced Killer Cells 
Expansion and Anti-tum or Features in vitro. Journal of Soochow University Medical Science Edition 2011; 31:247-9.

26. Golkar L, Ding XZ, Ujiki MB, et al. Resveratrol inhibits pancreatic cancer cell proliferation through transcriptional induction of macrophage inhibitory cytokine-1. J Surg Res 2007;138:163-9.

27. Létourneau S, Krieg C, Pantaleo G, et al. IL-2- and CD25-dependent immunoregulatory mechanisms in the homeostasis of T-cell subsets. J Allergy Clin Immunol 2009;123:758-62.

28. Chistiakov DA, Voronova NV, Chistiakov PA. The crucial

Cite this article as: Liu Y, Li J, Zhao L, Zhu J, Liu S, Wang H, Zhang Y. Effects of interleukin-2 concentration and administration method on proliferation and function of cytokine-induced killer cells. Transl Cancer Res 2021;10(9): 3930-3938. doi: 10.21037/tcr-21-556 role of IL-2/IL-2RA-mediated immune regulation in the pathogenesis of type 1 diabetes, an evidence coming from genetic and animal model studies. Immunol Lett 2008;118:1-5.

29. Wang C, Wei SJ. Research progress of CD4 + CD25 + Treg cells and tumor immunity. The Practical Journal of Cancer 2014;9:1196-9.

30. Cesana GC, DeRaffele G, Cohen S, et al. Characterization of CD4+CD25+ regulatory $\mathrm{T}$ cells in patients treated with high-dose interleukin-2 for metastatic melanoma or renal cell carcinoma. J Clin Oncol 2006;24:1169-77. 